\title{
Atendimento Fisioterapêutico ao Paciente em Cuidados Paliativos Oncológicos em Tempos de Pandemia por Covid-19: Recomendações de uma Unidade de Referência
}

doi: https://doi.org/10.32635/2176-9745.RBC.2020v66nTemaAtual.1113

\author{
Physiotherapeutic Care to the Patient in Oncological Palliative Care in Pandemic Times by COVID-19: Recommendations of \\ a Reference Unit \\ Atención Fisioterapéutica al Paciente en Atención Paliativa Oncológica en Tiempos Pandémicos por Covid-19: \\ Recomendaciones de una Unidad de Referencia
}

Ernani Costa Mendes ${ }^{\text {; }}$ Liziane Pereira Silva²; Patricia Almeida Chelles ${ }^{3}$; Francine Peres da Silva ${ }^{4}$; Juliana Miranda Dutra de Resende ${ }^{5}$

\section{INTRODUÇÃO}

A doença pelo coronavírus 2019 (coronavirus disease 2019 - Covid-19) é uma infecção viral, altamente contagiosa de caráter inflamatório, cuja maioria dos pacientes apresenta a forma leve (40\%) ou moderada (40\%) da doença, aproximadamente $15 \%$ tem a forma grave que requer suporte de oxigênio e 5\% dos casos evoluem de forma crítica com complicaçôes, como: insuficiência respiratória, falência respiratória aguda, sepse, choque séptico, tromboembolismo e /ou falência de múltiplos órgãos. Pode desenvolver, ainda, alteraçôes mentais e neurológicas como: delírio, encefalopatia, agitação, acidente vascular cerebral, meningoencefalite, comprometimento do olfato ou do paladar, ansiedade, depressão e problemas de sono ${ }^{1}$.

A forma mais grave da doença pode acometer indivíduos saudáveis de qualquer idade, mas ocorre predominantemente em adultos com idade avançada e com fatores de risco como: tabagismo, obesidade, diabetes mellitus, hipertensão arterial sistêmica, doenças cardíacas, doenças pulmonares crônicas, doença renal crônica e câncer, em especial nas neoplasias hematológicas, câncer de pulmão e doença metastática com estadiamento $\mathrm{IV}^{2}$.

Tendo em vista a disseminação da Covid-19 e sabendo que pacientes com câncer avançado fazem parte do grupo de risco para essa infecçáa ${ }^{3}$, é necessário reformular o fluxo de acompanhamento desse grupo, bem como elaborar estratégias para manter o controle de sintomas, apesar das regras de isolamento e restrição de circulação social em razáo da pandemia ${ }^{4}$.

Os pacientes com câncer avançado em cuidados paliativos diagnosticados com Covid-19 podem se beneficiar do acompanhamento da fisioterapia para abordagem e controle das complicaçóes que interferem em sua funcionalidade.

A fisioterapia está inserida na equipe multidisciplinar e, por meio de suas técnicas e recursos, tem como propósito minimizar as repercussóes físico-funcionais da doença, preservando a autonomia, independência e qualidade de vida ${ }^{4}$. Segundo o Código de Ética Profissional ${ }^{5}$, o fisioterapeuta presta assistência ao ser humano, tanto no plano individual quanto coletivo, participando da promoção da saúde e cuidados paliativos, sempre tendo em vista a qualidade de vida sem discriminação de qualquer forma ou pretexto.

De acordo com o status funcional e a necessidade de controle de sintomas, a assistência fisioterapêutica prestada acontece no ambulatório, assistência domiciliar (AD) ou internação hospitalar (IH). Segundo a nota técnica da Agência Nacional de Vigilância Sanitária (Anvisa) por conta da pandemia, é necessário seguir novas recomendaçôes para conter a transmissão e a disseminação do novo coronavírus durante qualquer abordagem à saúde. No cenário atual, a Academia Nacional de Cuidados Paliativos (ANCP) $)^{4}$ recomenda aos serviços alterar a assistência convencional para capacidade de contingência.

A abordagem sugerida pela ANCP é a substituição dos atendimentos presenciais por teleconsulta ou

${ }^{1}$ Fisioterapeuta. Doutor em Ciências da Saúde. Unidade de Cuidados Paliativos do Hospital do Câncer IV (HC IV). Instituto Nacional de Câncer José Alencar Gomes da Silva (INCA). Rio de Janeiro (RJ), Brasil. Orcid iD: https://0000-0003-2489-6107

${ }^{2}$ Fisioterapeuta. Especialista em Gerontologia. Unidade de Cuidados Paliativos do HC IV/INCA. Rio de Janeiro (RJ), Brasil. Orcid iD: https://orcid.org/0000-0002-6405-5153

${ }^{3}$ Fisioterapeuta. Especialista em Fisioterapia Pneumofuncional. Unidade de Cuidados Paliativos do HC IV/INCA. Rio de Janeiro (RJ), Brasil. Orcid iD: https://orcid. org/0000-0001-5687-0302

${ }^{4}$ Fisioterapeuta. Especialista em Fisioterapia Neurofuncional. Unidade de Cuidados Paliativos do HC IV/INCA. Rio de Janeiro (RJ), Brasil. Orcid iD: https://orcid. org/0000-0002-4239-9705

${ }^{5}$ Fisioterapeuta. Especialista em Fisioterapia Oncológica. Unidade de Cuidados Paliativos do HC IV/INCA. Rio de Janeiro (RJ), Brasil. Orcid iD: https://orcid. org/0000-0003-4232-4233

Endereço para correspondência: Ernani Costa Mendes. Rua Visconde de Santa Isabel, 274 - Vila Isabel. Rio de Janeiro (RJ), Brasil. CEP 20560-121. E-mail: ernanicmendes@gmail.com 
telemonitoramento, principalmente nos seguimentos de ambulatório e assistência domiciliar, visando a minimizar a exposição da contaminação pelo vírus. Essa recomendação também é respaldada pelo Conselho Federal de Fisioterapia e Terapia Ocupacional (COFFITO) na Resolução n. ${ }^{\circ}$ 516, de 20 de março de $2020^{7}$, que descreve a permissão para atendimento não presencial nas modalidades de teleconsulta, teleconsultoria e telemonitoramento, e garante ao fisioterapeuta autonomia e independência para determinar o paciente com indicação de atendimento presencial ou acompanhamento a distância, com base em evidências científicas quanto ao seu benefício.

Em toda modalidade de atendimento com avaliaçáo profissional presencial (IH, ambulatório ou AD), a abordagem ao paciente deve seguir as medidas de segurança recomendadas pela Comissão de Controle de Infecção Hospitalar $(\mathrm{CCIH})$ da unidade, fazendo uso racional dos equipamentos de proteção individuais (EPI) necessários e realizando medidas de precauçáo de disseminação da infecção no ambiente.

Um dos princípios dos cuidados paliativos é garantir a qualidade do cuidado e conforto até o final da vida, essa filosofia previne o sofrimento evitável e a distanásia ${ }^{8}$. Os pacientes encaminhados ao cuidado paliativo exclusivo sáo orientados quanto aos princípios dessa abordagem e assinam um Termo de Consentimento Livre e Esclarecido, que contém convençóes sobre ordem de não intubação $(\mathrm{ONI})$ e ordem de não reanimaçáo (ONR), além de receber orientaçóes, como, por exemplo, que a unidade não dispóe de Unidade de Terapia Intensiva (UTI), sendo assim, não serão submetidos à ventilação mecânica invasiva (VMI) e receberão medidas de manejo de sinais e sintomas relacionados à doença de base e às complicaçôes atuais.

\section{RECOMENDAÇÕES PARA O MANEJO FISIOTERAPÊUTICO DE SINTOMAS}

\section{DISPNEIA}

Assim como no câncer avançado, a dispneia é um dos sintomas de gravidade que demandam atendimento e internação de pacientes com Covid-1933.

Considerando que a ventilação não invasiva (VNI) é uma opçáo de escolha para o manejo da dispneia em pacientes em cuidados paliativos ${ }^{9}$, na especificidade da Covid-19, a experiência atual com insuficiência respiratória hipoxêmica demonstra alta taxa de falha na utilização da técnica. Com base na revisão da literatura, a recomendação é que a VNI não deve ser estratégia ventilatória de primeira linha. Se instituída, deve ser realizada com rigoroso uso de EPI, equipamentos e interfaces apropriados em virtude da liberação de aerossol, disseminação viral e grande risco de contaminação ${ }^{10}$.
Nos casos de queixa de dispneia, que não tenham indicação de VNI, são recomendadas estratégias para conforto e manejo desse sintoma, como: manutenção do ambiente tranquilo e ventilado, com as janelas abertas, resfriamento do rosto do paciente utilizando compressas frias, uso de roupa confortável, ajuste postural de preferência com cabeceira elevada e técnicas de relaxamento ${ }^{4}$.

Segundo Thomas et al. ${ }^{10}$,

A infecção respiratória ligada à Covid-19 está principalmente associada a uma tosse seca e náo produtiva; o envolvimento do trato respiratório inferior geralmente abrange pneumonite, ao invés de consolidação exsudativa. Nesses casos, as intervençôes respiratórias não são indicadas ${ }^{10}$.

Nos casos clínicos mais complexos, em que se observa a consolidação exsudativa com hipersecreção mucosa com dificuldade para mobilizar secreções, existe a indicação de fisioterapia respiratória e deve ser avaliada a especificidade de cada caso.

\section{FADIGA}

É um sintoma de grande prevalência tanto na Covid-19 $(44 \% \text { a } 70 \%)^{11}$ quanto no câncer avançado (>75\%), que impacta diretamente na funcionalidade ${ }^{12}$. Nos casos de fadiga intensa, propor um gerenciamento das atividades domiciliares com técnicas de conservação de energia, como: adaptação do ambiente para facilitar tarefas, substituir tarefas da posição ortostática para sentada, solicitar ajuda aos familiares e cuidadores, programar as atividades com diferentes níveis de exigências, partindo do grau de menor gasto energético, progredindo para o maior conforme tolerância do paciente, e facilitar o acesso aos materiais e dispositivos a serem usados ${ }^{13}$.

As intervençóes de fisioterapia para reabilitação na IH podem ser consideradas em casos de limitaçôes funcionais significativas. Estas deverão ser discutidas com a equipe multiplidisciplinar após a avaliação do estado clínico e físico do paciente, que deve apresentar funçáo respiratória e hemodinâmica estáveis ${ }^{10}$. A mobilização precoce deve ser encorajada, $\mathrm{o}$ incentivo funcional quanto às atividades dentro do quarto, como sentar-se fora do leito e realizar atividades de vida diária (AVD), são recomendaçóes básicas e essenciais para o início da recuperação funcional.

\section{OUTROS SINTOMAS RELACIONADOS AO CÂNCER AVANÇADO}

Além da dispneia e da fadiga, outros sinais e sintomas podem ser abordados pela fisioterapia, como: dor, metástase óssea e suas complicaçóes, alteraçôes venolinfáticas, entre outros ${ }^{14}$. Tais condiçóes clínicas não devem ser negligenciadas no momento da $\mathrm{IH}$, mas devem ser discutidas em equipe para definiçấo do momento 
adequado da abordagem, ponderando a exposição dos profissionais, a relação custo-benefício do atendimento e o critério de estabilidade clínica do paciente.

Os pacientes que tiverem alta hospitalar devem ser monitorados por intermédio de recursos como a teleconsulta ou o telemonitoramento. Mediante esse contato, estima-se o estado do paciente no domicílio tanto com relaçáo ao controle de sintomas quanto à funcionalidade. A partir daí, deve ser traçado um plano de tratamento com orientaçóes aos pacientes, familiares e cuidadores. Também pode ser considerada a necessidade de videochamada ou avaliação presencial nos casos em que o profissional julgar mandatório. Se o processo de acompanhamento na unidade for a $\mathrm{AD}$, recomenda-se o uso de cartilhas com orientações sobre exercícios, uso de órteses e de outros recursos fisioterapêuticos, que podem ser entregues à família por um profissional da equipe ou enviadas por meio de mídia eletrônica.

\section{CONCLUSÃO}

Em cuidados paliativos, a atuação da fisioterapia é focada no processo de reabilitaçấo dos pacientes, principalmente no que está relacionado à funcionalidade. Apesar de a abordagem fisioterapêutica ser idealmente presencial, em tempos da pandemia de Covid-19, urge a necessidade de contingenciamento social e adaptação do atendimento ao paciente, de forma que este seja contemplado em suas demandas. Assim, sabendo que o paciente oncológico em cuidados paliativos está em franco processo de perdas físicas, emocionais e espirituais, que repercutem diretamente em sua qualidade de vida, a continuidade do seu tratamento não poderá ser negligenciada, só assim o respeito à sua dignidade será garantido.

\section{CONTRIBUIÇÕES}

Todos os autores contribuíram igualmente na concepção e planejamento do estudo; na obtenção, análise e interpretação dos dados; na redação e revisão crítica e aprovaram a versão final a ser publicada.

\section{DECLARAÇÃO DE CONFLITO DE INTERESSES}

Nada a declarar.

\section{FONTES DE FINANCIAMENTO}

Não há.

\section{REFERÊNCIAS}

1. World Health Organization. Clinical management of COVID-19: interim guidance [Internet]. Geneva:
WHO; 2020 May 27 [cited 2020 June 17]. Available from: https://www.who.int/publications/i/item/clinicalmanagement-of-covid-19

2. Dai M, Liu D, Liu M, et al. Patients with cancer appear more vulnerable to SARS-COV-2: a multicenter study during the COVID-19 outbreak. Cancer Discov. 2020;10(6):783-91. doi: https://doi.org/10.1158/21598290.CD-20-0422

3. Sampaio SGSM, Dias AM, Freitas R. Orientaçôes do serviço médico de uma unidade de referência em cuidados paliativos oncológicos frente à pandemia de Covid-19. Rev Bras Cancerol. 2020;66(TemaAtual):e-1058. doi: https://doi.org/10.32635/2176-9745. RBC.2020v66nTemaAtual.1058

4. Academia Nacional de Cuidados Paliativos (BR). Posicionamento da Academia Nacional de Cuidados Paliativos sobre COVID-19 [Internet]. Sáo Paulo: ANCP; [2020] [acesso 2020 jun 15] Disponível em: https://www.dropbox.com/s/g77qi6xk2jc8rky/ FINAL_ANCP_Ebook_cuidados_COVID-19. pdf?HYPERLINK"https://www.dropbox.com/s/ g77qi6xk2jc8rky/FINAL_ANCP_Ebook_cuidados_ COVID-19.pdf? $\mathrm{dl}=0 " \mathrm{dl}=0$

5. Conselho Federal de Fisioterapia e Terapia Ocupacional (BR). Resolução n424, de 08 de julho de 2013. Estabelece o Código de Ética e Deontologia da Fisioterapia [Internet]. Diário Oficial da União, Brasília, DF; 2013 ago 1. Seção I [acesso 2020 jun 10]. Disponível em: https://www.coffito.gov.br/nsite/?p=3187

6. Agência Nacional de Vigilância Sanitária. Nota Técnica GVIMS/GGTES/ANVISA nº 04/2020: orientaçôes para serviços de saúde: medidas de prevenção e controle que devem ser adotadas durante a assistência nos casos suspeitos ou confirmados de infecção pelo novo coronavirus SARS-CoV-2 [Internet]. Brasília, DF: ANVISA; 2020 jan 30 [atualizada 2020 maio 08; acesso 2020 jun 17]. Disponível em: http:// portal.anvisa.gov.br/documents/33852/271858/ Nota+T\%C3\%A9cnica+n+04-2020+GVIMS-GGTESANVISA/ab598660-3de4-4f14-8e6f-b9341c196b28

7. Conselho Federal de Fisioterapia e Terapia Ocupacional (BR). Resolução no 516, de 20 de março de 2020. Dispóe sobre a suspensão temporária do Artigo 15, inciso II e Artigo 39 da Resolução COFFITO no 424/2013 e Artigo 15, inciso II e Artigo 39 da Resolução COFFITO no 425/2013 e estabelece outras providências durante o enfrentamento da crise provocada pela Pandemia do COVID-19 [Internet]. Diário Oficial da União, Brasília, DF; 2020 mar 23. Seçáo I, p. 184 [acesso 2020 jun 12]. Disponível em: https://www.coffito.gov.br/nsite/?p=15825

8. Academia Nacional de Cuidados Paliativos (BR). Manual de cuidados paliativos ANCP [Internet]. 2. ed. atual. São Paulo: ANCP; 2012 [acesso 2020 jun 10]. Disponível em: https://paliativo.org.br/download/manual-decuidados-paliativos-ancp/ 
9. Quill CM, Quill TE. Palliative use of noninvasive ventilation: navigating murky waters. J Palliat Med. 2014;17(6):657-61. doi: https://doi.org/10.1089/ jpm.2014.0010

10. Thomas P, Baldwin C, Bissett B, et al. Physiotherapy management for COVID-19 in the acute hospital setting: clinical practice recommendations. J Physiother. 2020;66(2):73-82. doi: https://doi.org/10.1016/j. jphys.2020.03.011

11. Center for disease Control and Prevention (US) [Internet]. Atlanta: CDC; [date unknown]. Interim clinical guidance for management of patients with confirmed coronavirus disease (COVID-19); 2020 [cited 2020 June 15]. Available from: https://www. cdc.gov/coronavirus/2019-ncov/hcp/clinical-guidancemanagement-patients.html

12. National Comprehensive Cancer Network (US). Cancerrelated fatigue-NCCN Guidelines (US) [Internet]. Rockledge (PA): NCCN; 2019 [cited 2020 June 16]. Available from: https://www.nccn.org/professionals/ physician_gls/pdf/fatigue.pdf

13. Veloso M, Jardim JR. Functionality of patients with chronic obstructive pulmonary disease: energy conservation techniques. J Bras Pneumol. 2006;32(6):580-6. doi: https://doi.org/10.1590/s1806-37132006000600017

14. Marcucci FCI. O papel da fisioterapia nos cuidados paliativos a pacientes com câncer. Rev Bras Cancerol. 2005;51(1):67-77. 